\title{
Brain tissue viscoelasticity in chronically shunted patients with headaches using Magnetic Resonance Elastography
}

\author{
Kristy Tan ${ }^{1 *}$, Adam L Sandler ${ }^{2}$, Avital Meiri ${ }^{1}$, Rick Abbott ${ }^{2}$, James T Goodrich², Eric Barnhill ${ }^{3}$, Mark E Wagshul ${ }^{1}$ \\ From Hydrocephalus 2015 \\ Banff, Canada. 18-21 September 2015
}

\section{Introduction}

Chronic headaches are a well-documented complaint of shunted hydrocephalic patients. However, it is also one of the signs of shunt malfunction. Cranial compliance deficiency may be a cause of chronic headaches in some chronically shunted patients with functioning shunts (often with slit or smaller than normal ventricles). This study aims to use a novel, non-invasive imaging technique, Magnetic Resonance Elastography (MRE) to investigate the role of brain viscoelasticity in pediatric hydrocephalic patients.

\section{Methods}

Shunt-dependent patients who developed hydrocephalus as infants were selected. Preliminary results from 12 patients (age 15-37, median age 23) who suffer from chronic headaches (excluding patients with abnormally large ventricles, defined as ventricular volume $<25 \mathrm{~cm} 3$ ) are shown.

MRE was performed by inducing a mechanical wave at $30 \mathrm{~Hz}$, transmitted through the zygomatic arches. Wave propagation speed was used to estimate viscoelasticity (shear modulus, $\mathrm{G}^{*}$ ). Images were motion and distortion corrected using MRE magnitude and field maps respectively. Image segmentation was performed on registered high-resolution images to produce CSF, white and gray matter masks using FSL. Ventricular volume was calculated from the CSF component.

\section{Results}

Good wave penetration was observed in MRE results allowing high quality data to be reconstructed. The

\footnotetext{
* Correspondence: kristy.tan@einstein.yu.edu

${ }^{1}$ Albert Einstein College of Medicine, USA

Full list of author information is available at the end of the article
}

viscoelasticity for gray matter was found to be positively correlated to white matter $(\mathrm{R} 2=0.97, \mathrm{p}<0.01)$. There was a positive correlation between the viscoelasticity of gray matter and ventricular volume that was statistically significant $(\mathrm{R} 2=0.60, \mathrm{p}=0.04)$. There was also a trend toward significance between the viscoelasticity of the white matter and ventricular volume $(R 2=0.49)$.

\section{Conclusions}

This pilot study demonstrates that MRE could be a powerful diagnostic tool to be used in pediatric hydrocephalic patients. Preliminary results show the brain to be more viscoelastic as ventricle size increases in patients indicating that compliance could be key in understanding the cause of headaches in chronically shunted patients. This study is ongoing with the aim of comparing control and patient data and correlating viscoelasticity to headache severity.

\section{Authors' details \\ 'Albert Einstein College of Medicine, USA. ${ }^{2}$ Department of Neurological Surgery, Albert Einstein College of Medicine/Children's Hospital at Montefiore, Bronx NY, USA. ${ }^{3}$ Clinical Research Imaging Centre, College of Medicine and Veterinary Medicine, University of Edinburgh, UK.}

Published: 18 September 2015

\section{References}

1. Bilston L, Tan K: Measurement of Passive Skeletal Muscle Mechanical Properties In Vivo: Recent Progress, Clinical Applications, and Remaining Challenges. Annals of Biomedical Engineering 2015, 43(2):261-273, doi: 10.1007/s10439-014-1 186-2.

2. Farnoush A, Tan K, Juge L, Bilston L, Cheng S: The effects of endoscopic third ventriculostomy on cerebrospinal fluid pressure in the cerebral ventricles. Journal of Clinical Neuroscience 2015.

3. Hatt A, Cheng S, Tan K, Sinkus R, Bilston L: MR Elastography Can Be Used to Measure Brain Stiffness Changes as a Result of Altered Cranial Venous Drainage During Jugular Compression. American Journal of Neuroradiology 2015 
4. Tan $K$, Cheng S, Juge L, Bilston L E: Characterising soft tissues under large amplitude oscillatory shear and combined loading. Journal of

Biomechanics 2013, 46(6):1060-1066, doi: 10.1016/j.jbiomech.2013.01.028.

5. Cheng S, Tan K, Bilston $L E$ : The effects of the interthalamic adhesion position on cerebrospinal fluid dynamics in the cerebral ventricles. Journal of Biomechanics 2010, 43(3):579-582.

doi:10.1186/2045-8118-12-S1-030

Cite this article as: Tan et al: Brain tissue viscoelasticity in chronically shunted patients with headaches using Magnetic Resonance

Elastography. Fluids and Barriers of the CNS 2015 12(Suppl 1):030.

Submit your next manuscript to BioMed Central and take full advantage of:

- Convenient online submission

- Thorough peer review

- No space constraints or color figure charges

- Immediate publication on acceptance

- Inclusion in PubMed, CAS, Scopus and Google Scholar

- Research which is freely available for redistribution

Submit your manuscript at www.biomedcentral.com/submit
Ciomed Central 